Annual Journal of Hydraulic Engineering,

JSCE VOL. 39 (1995)

\title{
BASIC SUTUDY ON THE WATER - SEAL SYSTEM IN UNDERGROUND STORAGE OF FUELS
}

\author{
by Kuniaki SATO*, \& Teruyuki FUKUHARA**
}

\begin{abstract}
A mumber of rock cavern's due to the water-seal system have been constructed to store a large amount of fuels like oils and liquified propane gas (LPG). The water-seal system is one of the most powerful techniques for piling the fuels through groundwater barrier. This paper studies key points of water - seal hydraulics theoretically and experimentally. This is focused on: (1) mechanism of water-seal system, and (2) gas penetration process after gas leakage. According to the results of the present study, it is suggested that the design depth of caverns is specified not only by hydrostatic pressure but also by capillary pressure and threshold pressure of gas penetration in wetted rocks.
\end{abstract}

Keywords: groundwater, water - seal system, gas penetration, fuels and rock store

\section{INTRODUCTION}

The stock piling of fuels like oils and liquified propane gas has been carried out in European countries, U.S.A. and several other countries after the World War II. The development of crude oil stock piling due to the water-seal system started in the Oil Underground Storage Method Testing Plant (Japan National Oil Corporation) at Kikuma, Ehime prefecture (November, 1981, storage volume: 25,000 k1). After this, three full scale stock piling plants with total volume 500 million $\mathrm{kl}$ were constructed at three different locations (Kuji, Iwate prefecture, Kikuma, Ehime prefecture and Kushikino, Kagoshima prefecture) ${ }^{1)}$. In these cases of crude oil stock piling, as long as the gas leakage is concerned, there is nothing to worry about it because of less gas pressure at the top of caverns. Taking an increasing interest in the liquified propane gas underground storage several years ago, a LPG underground storage method testing plant was built in Kurashiki, Okayama prefecture, and many precious data in practice were obtained through the testing plant in $1993^{2)}$. At present, a safety standard specification of LPG underground storage is authorizing by the High Pressure Gas Safety Institute of Japan. Some full - scale projects of LPG underground storage will be in practice in near future. A noted feature of LPG underground storage due to the water-seal system is to put a high gas pressure for liquidizing the propane gas in rock caverns. In this case the safety performance of the water - seal system owning to groundwater becomes a key subject, especially with the vaporized gas phase. In many practical cases of LPG underground storage the acting pressure is in the range of $8 \mathrm{kgf} / \mathrm{cm}^{2}-10 \mathrm{kgf} / \mathrm{cm}^{2}$ at a groundwater temperature $15^{\circ} \mathrm{C}$. The design depth of their cases corresponding to LPG sealing pressure is $80 \mathrm{~m}-100 \mathrm{~m}$ for different kinds of rock masses.

The most important subject with respect to the water-seal system has been paid

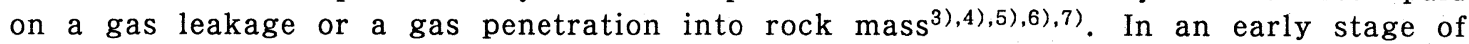
the study a safety criterion against the pressurized gas leakage was devoted to a critical

* Member of JSCE, Associate Professor, Dr. Eng., Hydroscience and Geotechnology Laboratory, Faculty of Enginnering, Saitama University, 255 Shimo - ohkubo, Urawa - shi, Saitama 338 Japan

** Member of JSCE, Associate Professor, Dr. Eng., Department of Architecture and Civil Engineering, Faculty of Engineering, Fukui University, 3-9-1 Bunkyo, Fukui 910 Japan 
hydraulic gradient $\boldsymbol{i}_{c}=1.0$ at the top of cavern (B. Åberg (1977)) and hydrostatic pressure. A design depth of storage cavern based on the criterion possibly; give, however, poor economy in its construction. This criticism has been repeated since many field data were obtained from two testing plants on crude oil (Kikuma plant) and LPG (Kurashiki). Regrettably, the criticism is still remained in these days because a large-scale field test includes many uncertainty factors in any time.

Giving attention to such a background of the water-seal system, the authors study the generation of gas leakage and gas seepage in fracture models and rock specimens theoretically and experimentally.

\section{TECHNICAL CONCEPT AND PRACTICES IN LPG UNDERGROUND STORAGE}

The purpose of the water - seal system is to store the fuels and gases (air) in rock caverns through groundwater. The principle of it is adopted to not only underground storage of fuels but also a compressed air energy storage system (CAES) for a storage technique of electric power. A concept of the water - seal system and a scenario on upward penetration process of air bubbles in rock mass and sedimentary deposits are shown in Fig. 1. An expected performance of the water - seal system for both gas phase and liquid state must be established by the hydrodynamic (near hydrostatic) groundwater pressure acting on surroundings of cavern wall as well as penetration resistance originated in surface tension (or capillary force) in existing fractures. Namely, the waterseal system is maintained by both two forces, and it may be called "hydrodynamic barrier" against the leakage of the gas and liquid state fuel. On the other hand, the leaked gas into rock mass will become a number of bubbles around cavern wall according to a strong surface tension, and a part of their bubbles may move upward through pores in rock and fractures in rock mass. The driving force of their bubbles is a buoyancy in groundwater.

The moving bubbles are surely affected by a strong resistance in upward penetration process as well

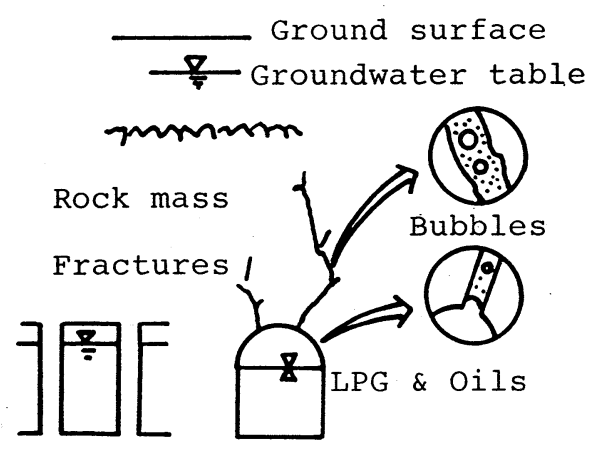

(a) Piller \& room cavern cavern

Fig.1 Water - Seal System and Groundwater as the dissolving effect into the groundwater. In other words, the water - seal system is protected by the resistance of moving bubbles, and it may be called "groundwater barrier". In designing concept of cavern depth the engineers have put the priority on the water-seal system coming from the hydrodynamic barrier.

$$
\text { Usually, the designing depth } \boldsymbol{H} \text { of a } \operatorname{cavern}^{8), 9)} \text { has been determined by }
$$

$$
H \geqq a p_{m}+h_{a}, \cdots \cdots \cdot(1) \text {, or } H>p_{m}+h_{s}+h_{g}, \cdots \cdots \cdots
$$

where $\boldsymbol{H}$ : designing depth of a cavern $(\mathrm{m}), \boldsymbol{a}:$ a constant depending on kinds of storing objectives and geology of rock mass, $\boldsymbol{p}_{m}$ : maximum pressure of gas phase in cavern $(\mathrm{m})$, $\boldsymbol{h}_{\boldsymbol{a}}$ : additional safety height $(\mathrm{m}), \boldsymbol{h}_{\boldsymbol{s}}$ : shape factor depending on cavern geometry and neighboring caverns $(\mathrm{m})$, and $\boldsymbol{h}_{\boldsymbol{g}}$ : safety margin height introduced to cope with groundwater table irregularity $(\mathrm{m})$. The design concept of cavern depth is based upon that the sum of a groundwater height equal to the maximum gas pressure in cavern and additional safety height above cavern must be conserved. The concept of both Eqs. (1) and (2) is common, and it is very important in economical point of view. In practice the engineers feel pressure by how to decide the constant and additional safety height in Eqs. for different geology, groundwater and economy. If the required groundwater height $\mathrm{H}$ above cavern can not conserved geohydrologically in natural conditions, the engineers are obliged to keep it by a set of artificial recharge pits or tunnels with groundwater feeding boring holes. 
Theoretically, the following discussion might be not necessary if a complete evidence were given to us through the hydrodynamic barrier. It is not, however, so easy in practice. Thus, the engineers have discussed the possible motion of bubbles in groundwater environment (barrier).

A conceptual model of a bubble motion in pores and a fracture is demonstrated in Fig.2. The motion of the bubble is dynamically expressed by,

$$
\left(\rho_{g}+\boldsymbol{a} \rho_{w}\right) d q_{g} / d t=\text { (buoyancy, contact friction, drag force, }
$$

surface tension and small forces),

$$
\boldsymbol{p}_{g} \boldsymbol{v}_{g}=\text { Const. }
$$

where $\rho_{g}:$ gas density, $a:$ vertual mass factor ( $\fallingdotseq 0$ in pores), $\boldsymbol{\rho}_{w}$ : water density, $\boldsymbol{q}_{g}:$ gas velocity, $\boldsymbol{t}:$ time, $\boldsymbol{p}_{g}:$ gas pressure in a bubble and $\boldsymbol{v}_{g}$ : volume of a bubble.

A gas bubble does move according the buoyancy under the resistance caused by those forces. Because of many difficulties to clarify the contact friction, surface tension and small forces for various pores and fractures, several authors have studied the motion of a bubble in a simplified uniform interstice ${ }^{(3),(4) \text {, }}$ (6). They imaged in their studies that there would exist a critical velocity $\boldsymbol{q}_{g c}$ which an upward motion of the bubble in the simplified uniform interstice might stop in a balanced state between drag

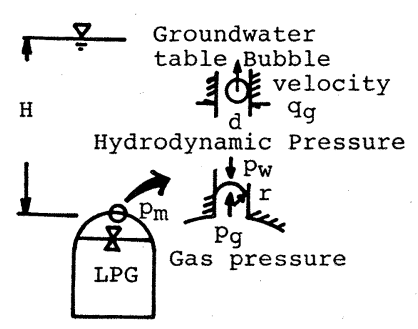

Fig.2 Model of a Bubble Motion force and buoyant force. In addition, the concept of critical velocity in the interstice would be applied to the motion of a gas bubble in a representative fracture of cavern. A critical hydraulic gradient $\boldsymbol{i}_{c}$ corresponding to the critical velocity in the fracture would probablly appear at the top of cavern. B. A berg (1977) proposed $i_{c}=1.0$ just after a gas bubble appeared in the vicinity of cavern wall, and other authors pointed out that $\boldsymbol{i}_{c}$ is less than 1.0 through many experimental data in laboratory.

The following discussion is concentrated on the water-seal system to disclose the theoretical background and experimental evidence which have been left to be vague.

\section{LEAKAGE MECHANISM OF GAS AND GAS SEEPAGE IN ROCKS}

\subsection{Gas Penetration Theory and Experimental Results}

A target of the water - seal system is preferably to the gas leakage in gas phase of LPG storage cavern nevertheless the performance of the system is required in both gas and liquid phases. The following discussions are laid on the gas penetration in fracture models and gas seepage in rocks.

Let us consider a gas penetration model in a fracture as shown in Fig.2.

A gas penetration slug in a single fracture with width $\boldsymbol{d}$ (radius : $r$ ) may move under the dynamic balance of groundwater pressure $\boldsymbol{p}_{w}$ and gas pressure $\boldsymbol{p}_{g}$ in cavern. The gas penetration slug is subjected to intruding force like surface tension and wall friction when it goes upward. An dynamic equation between capillary pressure $\boldsymbol{p}_{c}$ and surface tension $\boldsymbol{\sigma}$ is,

$$
\boldsymbol{p}_{c}=\left|\boldsymbol{p}_{w}-\boldsymbol{p}_{g}\right|=\boldsymbol{\sigma}\left(1 / \boldsymbol{r}^{\prime}+1 / \boldsymbol{r}^{\prime \prime}\right)=2 \boldsymbol{\sigma} / \boldsymbol{r}, \ldots .
$$

where $\boldsymbol{r}^{\prime}$ and $\boldsymbol{r}^{\prime \prime}$ : differernt curvetures of a curved gas - water interface.

The equation (5) discloses that the resisting force against the gas slug penetration is equal to the capillary

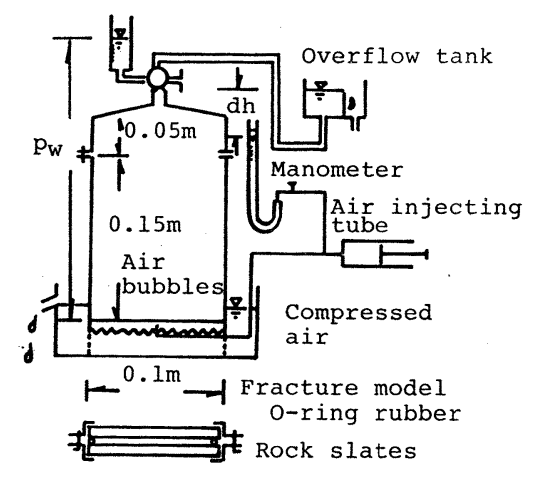

Fig.3 Gas Penetration Test in a Single Fracture 
force resulting from the capillary pressure in an inlet of fracture. Practically, it seems to be many small cracks and fractures around cavern wall. The capillary force against the gas leakage is inversely proportional to the width of opening cracks and fractures.

In order to make clear the validity of the theorectical consideration, the gas penetration tests in single fracture with different opening width are carried out in laboratory. An experimental apparatus of the tests is composed of (1) fracture model, (2) gas (air) injection tube with manometer and (3) overflow tank for intersticial flow as shown in Fig.3. Main purpose of the tests is the finding of critical hydraulic gradient or water pressure in starting gas penetration.

The testing procedure of gas penetration is as follows. The fracture model consists of two rock slates (height $: 0.15 \mathrm{~m}$ and width $: 0.1 \mathrm{~m}$ with $0.01 \mathrm{~m}$ in thickness), and the interstice (or fracture opening) of the slates is adjusted by $\mathrm{O}$-section ring rubber in the range of $0.1-1.0 \mathrm{~mm}$. The lithology of slates is several rocks (andesite, tuff and granite) and glass (rock properties are given in Table-1), and the surface of slates is smoothly polished. The air is injected into a small reservoir at the bottom of fracture model through air injection tube. The air pressure is measured by a manometer, and it has in the range of $2 \mathrm{kpa}-3 \mathrm{kpa}$. The water flow in fracture model is generated by regulating the overflow tank after keeping a required fracture width. The penetration of air into fracture is observed by a bubble generation in the upper ponding reservoir of fracture model, in addition to by pulsating manometer head. Temperature is maintained at $20^{\circ} \mathrm{C}$ and all tests are repeated for different fracture width in the same way.

The relationships between fracture width $\boldsymbol{d}$ and hydraulic gradient $i$ are given in Fig.4. According to their testing results for various rock slates, the generation of air penetration into fractures depends upon the fracture width $\boldsymbol{d}$. The upward movement of generated bubbles due to buoyant force and surface tension is constrained and pushed back under hydraulic gradient (drag force caused by seepage velocity). This fact will support the fluid mechanical concept on the critical hydraulic gradient $\boldsymbol{i}_{c}$ in the early paragraph. On the other hand, the experimental

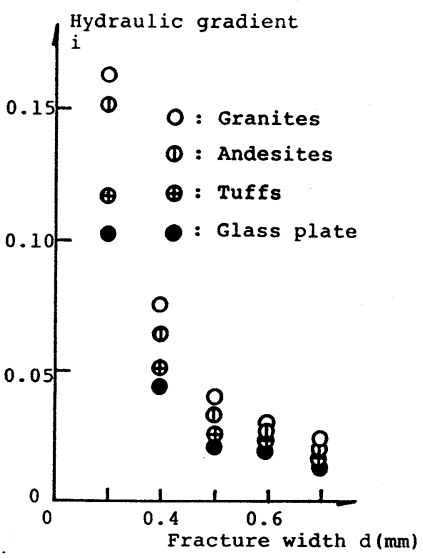

Fig.4 Relationships between $\boldsymbol{d}$ and $\boldsymbol{i}$ relationships between $\boldsymbol{p}_{g} / \boldsymbol{p}_{w}$ and $\boldsymbol{d}$ to examine the surface tension effect $(2 \sigma / \boldsymbol{r})$ against gas leakage in Eq. (5) are shown in Fig.5. For the sake of comparison some of relationships which are obtained from the similar experiments in higher water pressure $\boldsymbol{P}_{\boldsymbol{w}}>$ $3 K \boldsymbol{K a}$ are included in Fig. 5. Their results proves that the cappilary pressure $\boldsymbol{p}_{c}$ will break out when gas bubbles with diameter $2 \mathbf{r}$ penetrate into single fracture with width d. Because of the surface tension the values of $\boldsymbol{p}_{g} / \boldsymbol{p}_{w}$ are larger than 1.0 except several ones at the higher water pressure in wide fractures. The effect of surface tension for penetrating the gas slug decreases with increasing fracture width. If there is no effect of surface tension under a balance of water pressure with gas one, $\boldsymbol{p}_{g} / \boldsymbol{p}_{w}=1.0$ from Eq. (5). The effect will strongly appear in response to lower acting water pressure. It is concluded through gas penetration experiments that the empirical equations (1) and (2) may include the capillary effect in safety factor $\boldsymbol{a}$ or safety margin height $\boldsymbol{h}_{\boldsymbol{g}}$.

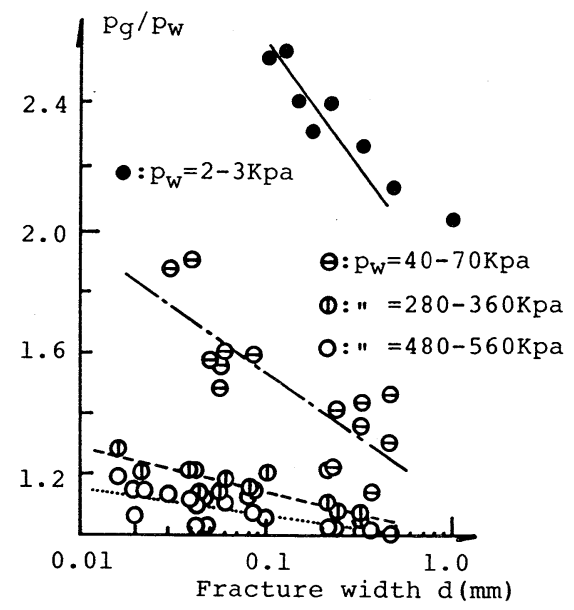

Fig.5 Relationships between $\boldsymbol{p}_{g} / \boldsymbol{p}_{w}$ and $\boldsymbol{d}$ (in Comparison with Those at Higher Water Pressure $\left.\boldsymbol{P}_{\boldsymbol{w}}>3 \boldsymbol{K} \boldsymbol{p a}\right)^{7}$

\subsection{Gas Permeability Tests of Rocks}

In order to determine the water - seal effect (permeability) of dried and wetted rocks in acting gas pressure, the gas permeability tests are done using a newly-designed apparatus as shown in Fig.6. The apparatus consists of (1) pressure cylinder of rock 
Table - 1 Gas Permeability of Rocks

\begin{tabular}{|c|c|c|c|c|}
\hline Samples & $\begin{array}{c}\text { Dried Effective } \\
\text { Porosity } \\
\lambda_{\mathrm{o}}(\%)\end{array}$ & $\begin{array}{c}\text { Dried Intrinsic } \\
\text { Permeability } \mathrm{k}_{4} \\
\left(10^{-16} \mathrm{~m}^{2}\right)\end{array}$ & $\begin{array}{l}\text { Wetted Effec- } \\
\text { tive Porosity } \\
\lambda_{\mathrm{st}}(\%)\end{array}$ & $\begin{array}{l}\text { Netted Intri- } \\
\text { nsic Permea- } \\
\text { bility } \mathrm{k}_{s} \\
\left(10^{-116} \mathrm{~m}^{2}\right)\end{array}$ \\
\hline Emochi Andesite & 12. 96 & 1.120 & 1.12 & 0.054 \\
\hline $\begin{array}{l}\text { Shin-Komatus } \\
\text { Andesite }\end{array}$ & 3.54 & 6.184 & 1.45 & 3.641 \\
\hline Izu Tuff & 22.43 & 1. 899 & 2.67 & 0.047 \\
\hline Shirakawa Tuff & 21.30 & 69.000 & 9.79 & 8.150 \\
\hline Teisen Granite & 0.74 & 0.178 & 0.43 & 0.050 \\
\hline Inada Granite & 0.67 & 0.127 & 0.21 & 0.047 \\
\hline Cement Hortar & 23.57 & 16.92 & 2. 49 & 0.154 \\
\hline
\end{tabular}

sample (height : $200 \mathrm{~mm}$, diameter : $106 \mathrm{~mm}$, stainless steel with thickness $10 \mathrm{~mm}$ ), (2) rock sample (height: $0.15 \mathrm{~m}$, diameter : $0.05 \mathrm{~m}$ ), (3) gas (air) pressure gauge (measurable range : $0-100$ $\left.\mathrm{kgf} / \mathrm{cm}^{2}\right)$, (4) digital pressure \& temperature recorder (accuracy: 1/100), (5) air flow rate meters (measurable ranges : $0-10 \mathrm{~cm}^{3}$ and 0 $\left.-100 \mathrm{~cm}^{3}\right)$ and (6) side pressure loading system of rock sample (maximum loading pressure: $\left.80 \mathrm{kgf} / \mathrm{cm}^{2}\right)$.

The experimental procedure is as follows : All air permeability tests are separately carried out using both dried and wetted rock samples. Several screws around the pressure cylinder of rock sample are settled after putting a rock sample with rubber sleeve tube into it. The rock sample is squeezed by acting side water pressure connected with the air compressor. Thus, the air seepage will generate from one end of rock sample to another end of it through a partial opening of compressed air tank. The air flow rate can be meassured by the flow rate meter against a given air pressure. The testing procedure is repeated for different acting air pressures. The same procedure is adopted for both dried and wetted rock samples under a constant temperature $23^{\circ} \mathrm{C}$.

The averaged air permeabilites and rock porosities are listed in Table -1 . The porosity is found by the weighing method of rock sample, and the permeability $\boldsymbol{K}$ is determined by,

$$
\boldsymbol{K}=\left(2 \boldsymbol{Q} \mu_{a} / \boldsymbol{A}\right) \boldsymbol{p}_{a r} /\left(\boldsymbol{p}_{a 0}^{2}-\boldsymbol{p}_{a l}^{2}\right)
$$

where $\boldsymbol{Q}$ : air flow rate, $\boldsymbol{\mu}_{a}$ : viscosity of air at a given temperature and an averaged pressure (integrated average) $\boldsymbol{p}_{a r}, \boldsymbol{A}$ : cross sectional area of rock sample and $\boldsymbol{p}_{a 0}, \boldsymbol{p}_{\mathrm{al}}$ : air pressures at upper end and lower end respectively.

The threshold air pressures that begin the air seepage in wetted rock samples are recognized in Fig.7, and their values depend upon the kinds of rock samples. The flow rate of wetted rocks reduces to $5 \%-30 \%$ of dried one. The correlations between $\mathbf{K}_{\mathbf{s t}} / \mathbf{K}_{\mathbf{d}}\left(\mathbf{K}_{\mathrm{st}}\right.$ : permeability of wetted rock and $K_{d}$ : permeability of dried rock) and $\lambda_{s t} / \lambda_{d}\left(\lambda_{s t}\right.$ : porosity of wetted rock and $\lambda_{d}$ : porosity of dried rock) from Table -1 are shown in Fig.8. It is found that the wetted permeability may increase with increasing wetted porosity because a part of void water is easily pushed out from the rock in larger wetting state. Gas permeability tests of wetted rocks illuminate that gas flow resistance through

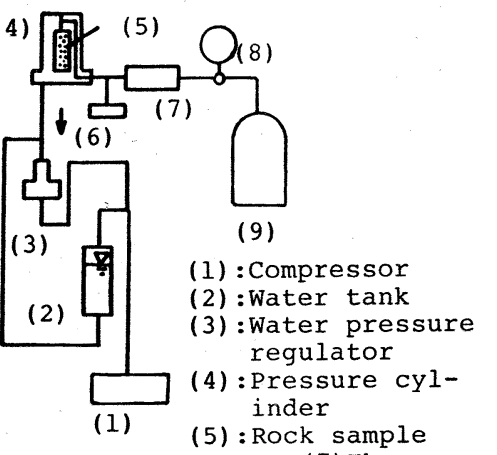
(6) : Pressure gage, (7) Thermometer, (8): Pressure regulating valve, (9): Compressed air tank

Fig.6 Apparatus of Gas Permeability Tests in Rocks 
a lot of partially wetted pores is not ignored in the water - seal system, and engineers derive benefit from its performance in designing rock caverns.

\section{CONCLUSION}

The planner of underground development is usually required to make public an environmental impact statement of the project and also to take several licenses with respect to safety, fire defense and realization of the development beforehand. A full performance of the water - seal system in underground storage of fuels becomes a pivot of its technology to clear the screening of governmental laws as well as construction specifications. In underground storage of liquified propane gas (LPG), the maximum gas pressure in cavern is in the range of $8 \mathrm{kgf} / \mathrm{cm}^{2}-10 \mathrm{kgf} / \mathrm{cm}^{2}$.

This paper aimed at to make clear hydraulic principle of the water-seal system in LPG underground storage. The results can be summarized as follows:

(1) The safety against the gas leakage in LPG underground storage is protected by the hydrodynamic barrier and groundwater barrier.

(2) The hydraulic performance in the water-seal system is realized through surface tension and hydrodynamic (nearly hydrostatic) pressure.

(3) A restrain of gas leak - out from LPG storage cavern is inversely proportional to the opening width of fractures, and an upward movement of gas bublle may be suppressed by water velocity in fracture.

(4) The threshold pressure to generate gas (air) seepage in rocks was recognized experimentally, and the permeability of wetted rocks surely becomes smaller than that of dried ones.

Finally, it is no exaggeration to say that the design criterion (or standard) of cavern depth in the past has been in safe side.

\section{REFERENCES}

1) Japan National Oil Corporation: Petroleum Stockpiling in Japan, pp.1-17, 1994

2) Japan National Oil Corporation: LPG Underground Storage Method Testing, pp.1 9,1993

3) Bengt Åberg: Prevention of gas leakage from unlined reservoirs in rock, Proc. Rock Store '77, Vol. 2, pp.175 - 189, 1977

4) Bengt Åberg: Pressure distribution around satationary gas bubbles in water saturated rock fractures, Proc. Int. Conference on Storage of Gas in rock Caverns, Trondheim, Norway, pp.77-86, 1989

5) K. Miyashita \& K. Sato: An experimental study of two-phases flow of air and water in the jointed model, Proc. Soils and Foundation, Vol. 24, No.4, pp.155-162, Dec., 1984 (in Japanese)

6) K. Nakagawa, H. Komata, K. Miyashita \& M. Kurata: Prevention of leakage of compressed air stored in unlined rock caverns, Proc. JSCE, Vol. 370/III -5 , pp.233-241, 1986

7) T. Sakaguchi, Y. Ito, K. Sato \& T. Shimizu : Fundamental study of gas seepage in rock and open-crack, Proc. of Japan Society of Civil Engineers (JSCE), No.445/III - 18, pp. $17-25,1992$

8) Japan National Oil Corporation: Report of LPG Stock Piling Technology, pp.1-194, March, 1990

9) Dames \& Moore Pty Ltd. : Environmental Impact Statement-Moilineux Facility LPG Storage, Sydeny, Australia, pp.1-385, 1992 